\title{
Penyisihan Krom pada Pengolahan Air Limbah Penyamakan Kulit Menggunakan Metode Elektrokoagulasi
}

\author{
Lina Hasyyati ${ }^{1 *}$, Etih Hartati ${ }^{2}$, Djaenudin ${ }^{3}$ \\ ${ }^{1,2}$ Teknik Lingkungan, Fakultas Teknik Sipil dan Perencanaan Institut Teknologi Nasional (Itenas), Bandung \\ ${ }^{3}$ Loka Penelitian Teknologi Bersih, Lembaga Ilmu Pengetahuan Indonesia (LIPI), Bandung \\ "Koresponden email: linahasyyati21@gmail.com
}

Diterima: 15 September 2020

Disetujui: 1 Oktober 2020

\begin{abstract}
Tanning is the process that converts animal hides and skin into stable and imputrescible products called leather. The production processes in a tanning use chromium sulfat. Chrome metal is a heavy metal that is toxic, so the waste water from the leather tanning process will pollute the environment if it is not treated. In this research, wastewater treatment is used by electrocoagulation method to determine the effect of operating on the chromium removal to obtain optimal conditions. In this study, electrocoagulation experiments were using aluminum electrodes. Electrocoagulation process was carried out in 9 variations with parameters $\mathrm{pH}$, electrical current and time where $\mathrm{pH}$ was set at $\mathrm{pH}$ 7. Electrical current done on 0.5 $\mathrm{A}, 1 \mathrm{~A}$, and $1.5 \mathrm{~A}$. Time done in 1 hour, 2 hours and 3 hours. The experiment results were analyzed by comparing the concentration before processing and concentration after processing to obtain efficiency. Based on the experimental result on 9 variations, the variation that has the highest efficiency is at electrical current 1.5 Ampere and time 3 hours. This variation can remove $78.95 \%$ chrome concentration from $245.1 \mathrm{mg} / \mathrm{L}$ to $51.6 \mathrm{mg} / \mathrm{L}$.
\end{abstract}

Keywords: wastewater, heavy metal, leather tanning industry, electrocoagulation, total chrome,

\begin{abstract}
Abstrak
Industri penyamakan kulit merupakan industri yang mengolah kulit mentah menjadi kulit tersamak. Proses produksi penyamakan kulit menggunakan senyawa kromium sulfat. Kromium merupakan logam berat yang bersifat toksik sehingga limbah dari proses penyamakan kulit dapat berbahaya bagi lingkungan, apabila limbah tidak diolah terlebih dahulu. Pada penelitian ini, air limbah dari industri penyamakan kulit dilakukan pengolahan dengan metode elektrokoagulasi untuk menentukan efek operasi pada penyisihan konsentrasi krom agar mendapatkan kondisi yang optimal. Elektroda yang digunakan terbuat dari alumunium. Proses elektrokoagulasi dilakukan pada 9 variasi dengan pengaturan pada parameter arus listrik, dan waktu operasi. Sampel air limbah yang digunakan diatur kondisinya pada $\mathrm{pH}$ 7. Pengaturan arus listrik dilakukan pada 0,5 A, $1 \mathrm{~A}$, dan 1,5 A. Variasi waktu operasi yang dilakukan yaitu pada 1 jam, 2 jam, dan 3 jam. Sampel hasil pengolahan yang didapat kemudian dianalisis dengan membandingkan antara konsentrasi krom total awal air limbah dengan konsentrasi krom total hasil setelah dilakukan pengolahan menggunakan metode elektrokoagulasi sehingga diperoleh presentase efisiensi penyisihan. Berdasarkan hasil percobaan dari 9 variasi didapatkan, variasi yang memiliki efisiensi tertinggi adalah pada variasi arus listrik 1,5 Ampere dan waktu pengolahan 3 jam. Pada variasi ini dapat menyisihkan krom sebanyak 78,95\% dari konsentrasi krom 245,1 mg/L menjadi 51,6 mg/L.
\end{abstract}

Kata kunci: elektrokoagulasi, limbah, logam berat, industri penyamakan kulit, krom total

\section{Pendahuluan}

Pembangunan industri merupakan pembangunan yang dapat memberikan kontribusi bagi perekonomian Indonesia. Pembangunan di sektor industri memberikan dampak positif dan negatif. Dampak positif diharapkan dapat meningkatkan taraf hidup manusia, memperbesar kesempatan kerja, dan meningkatkan pembangunan. Namun, dampak negatif dari pembangunan industri salah satunya adalah menimbulkan pencemaran lingkungan akibat limbah yang dikeluarkan dari proses produksi pada kegiatan industri [1].

Industri penyamakan kulit merupakan industri yang mengolah kulit mentah menjadi kulit tersamak (leather). Proses penyamakan dilakukan untuk melindungi kulit dari pengaruh lingkungan seperti degradasi mikrobial, panas, keringat, atau kelembaban [2]. Proses produksi penyamakan kulit menggunakan senyawa kromium sulfat. Kromium sulfat tidak semuanya dapat terserap pada proses 
produksi sehingga terdapat krom yang ikut terbuang pada limbah cair. [3]. Kromium merupakan salah satu logam berat yang bersifat toksik, tingkat toksisitasnya tergantung pada valensi ionnya, toksisitas $\mathrm{Cr}^{+6}$ kurang lebih 100 kali toksisitas $\mathrm{Cr}^{3+}$. Selain itu $\mathrm{Cr}^{6+}$ bersifat sangat korosif dan karsinogenik [4].

Limbah cair dari proses penyamakan kulit akan mencemari lingkungan, terutama terhadap badan air jika tidak dilakukan pengolahan terlebih dahulu. Untuk mengatasi masalah tersebut diperlukan alternatif pengolahan limbah penyamakan kulit yang efektif dan efisien. Elektrokoagulasi telah menarik banyak perhatian dalam aplikasi pengolahan limbah cair di industri.

Elektrokoagulasi adalah teknologi yang menggabungkan manfaat koagulasi, flotasi, dan elektrokimia [5]. Proses koagulasi merupakan destabilisasi koloid dengan adanya pemberian koagulan, flokulasi merupakan penggumpalan partikel-partikel kecil menjadi gumpalan yang lebih besar sehingga mudah mengendap [6]. Sedangkan metode elektrokoagulasi meniadakan bahan kimia sebagai koagulan dan flokulan, akan tetapi koagulan dibangkitkan dengan cara elektrolisis [7]. Kedua metode menargetkan pemisahan partikel dari air limbah melalui destabilitasi/menetralkan gaya tolak yang menjaga agar partikel tetap tersuspensi dalam air. Keunggulan elektrokoagulasi diantaranya menghasilkan lumpur rendah, flok relatif besar, mengandung lebih sedikit air yang terikat, lebih stabil, dan dapat disaring [8].

Proses elektrokoagulasi dilakukan pada reaktor yang didalamnya terdapat elektroda berupa katoda dan anoda sebagai penghantar arus listrik searah (DC), elektroda yang digunakan tercelup dalam larutan limbah sebagai elektrolitnya. Parameter yang mempengaruhi efektivitas elektrokoagulasi adalah tegangan dan waktu operasi, pH, alkalinitas, konduktivitas reaktor dan elektroda elektrokoagulasi [9]. Pada penelitian ini, dilakukan pengolahan dengan elektrokoagulasi untuk menentukan efek operasi parameter arus listrik dan waktu operasi pada penyisihan krom total agar mendapatkan kondisi yang optimal untuk penyisihan krom pada air limbah penyamakan kulit.

\section{Metodologi Penelitian}

\section{Lokasi dan Metode Penelitian}

Penelitian dilakukan di Laboratorium Loka Penelitian Teknologi Bersih LIPI Bandung pada Februari sampai Maret 2020. Pada penelitian ini dilakukan percobaan metode elektrokoagulasi dengan sistem batch pada volume $1 \mathrm{~L}$ sebanyak 9 variasi yang dilakukan pengaturan arus listrik dan durasi operasi. Pengaturan arus listrik dilakukan pada 0,5 A, $1 \mathrm{~A}$, dan 1,5 A. Pengaturan durasi dilakukan pada waktu 1 jam, 2 jam, dan 3 jam.

\section{Prosedur}

Reaktor tempat dilakukan proses elektrokoagulasi menggunakan gelas kimia berukuran $1 \mathrm{~L}$ yang didalamnya terdapat dua buah elektroda yang berfungsi sebagai anoda dan katoda. Elektroda yang digunakan terbuat dari plat alumunium dengan ukuran masing-masing plat $6 \mathrm{~cm} \times 15 \mathrm{~cm}$. Elektroda disimpan pada penyangga dengan jarak antar elektroda yaitu $4 \mathrm{~cm}$.

Sebanyak $1 \mathrm{~L}$ sampel limbah penyamakan kulit dimasukkan ke dalam gelas kimia, kemudian diatur pH sampel pada pH 7 yang merupakan pH netral. Sampel awal yang memiliki pH 8,31 diturunkan menjadi $\mathrm{pH} 7$ dengan menggunakan $\mathrm{H}_{2} \mathrm{SO}_{4}$ pekat. Selanjutnya sampel dipindahkan ke dalam reaktor yang telah disiapkan. Elektroda dihubungkan dengan arus listrik yang dialirkan melalui rectifier sesuai dengan variasi yang ditentukan (Arus listrik 0,5 A, $1 \mathrm{~A}$, dan 1,5 A). Perlakuan proses elektrokoagulasi dilakukan pada waktu operasi sesuai dengan variasi (1 jam, 2 jam, 3 jam).

Selama proses elektrokoagulasi berlangsung dilakukan pengukuran $\mathrm{pH}$ dan suhu pada setiap variasi percobaan sebanyak 10 kali selama proses berlangsung untuk mengetahui perubahan $\mathrm{pH}$ dan perubahan suhu yang terjadi selama proses elektrokoagulasi. Pengukuran $\mathrm{pH}$ dan suhu dilakukan dengan menggunakan $\mathrm{pH}$ meter dan thermometer. Setelah limbah penyamakan kulit selesai dilakukan pengolahan elektrokoagulasi kemudian dimasukan ke dalam kerucut inhoff untuk dilakukan proses pengendapan. Supernatant yang didapatkan dilakukan pengujian terhadap parameter krom total (Cr-T). Pengukuran parameter krom total dilakukan dengan metode SNI 6989.17:2009 Cara uji krom total (Cr-T) secara Spektrofotometri Serapan Atom (SSA) - nyala.

Hasil percobaan yang didapat kemudian dianalisis dengan membandingkan antara karakteristik awal air limbah dengan hasil setelah dilakukan pengolahan menggunakan elektrokoagulasi sehingga diperoleh presentase efisiensi penyisihan.

\section{Hasil dan Pembahasan Proses Elektrokoagulasi}

Percobaan proses elektrokoagulasi pada pengolahan limbah penyamakan kulit bertujuan untuk mengetahui pengaruh arus listrik dan waktu pengolahan terhadap penurunan krom untuk mendapatkan 
kondisi yang optimum. Pada proses elektrokoagulasi terjadi perubahan pH, suhu, dan massa anoda. Berikut pembahasan mengenai perubahan yang terjadi selama proses elektrokoagulasi.

a. Perubahan pH

Perubahan $\mathrm{pH}$ yang terjadi selama proses elektrokoagulasi yang dilakukan dapat dilihat pada Gambar 1 sampai Gambar 3.

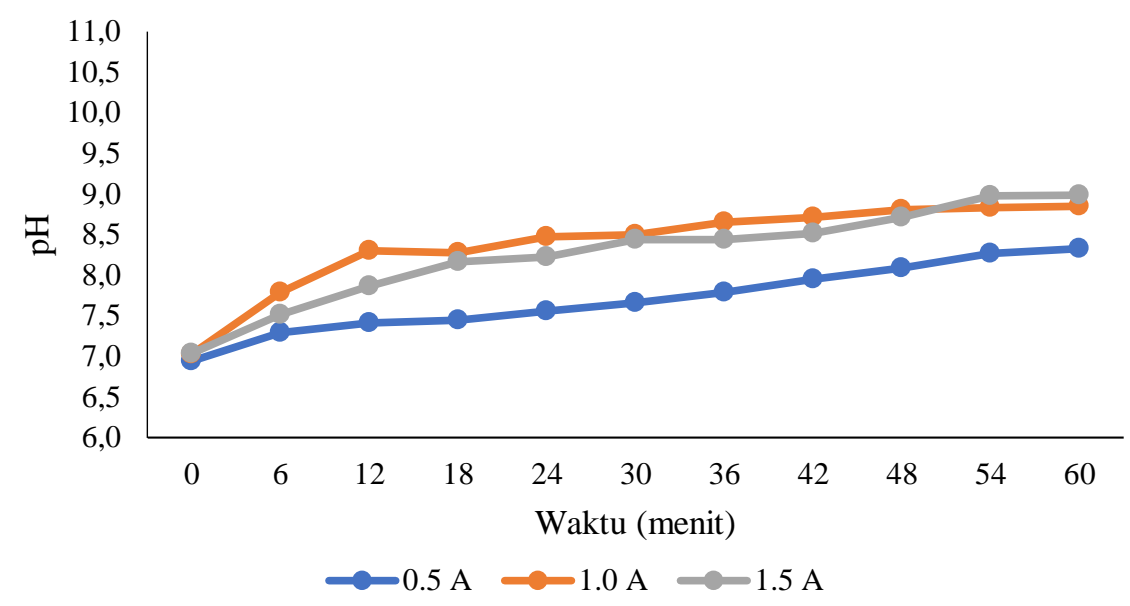

Gambar 1. Kurva perubahan pH pada waktu 1 jam Sumber: Hasil analisis, 2020

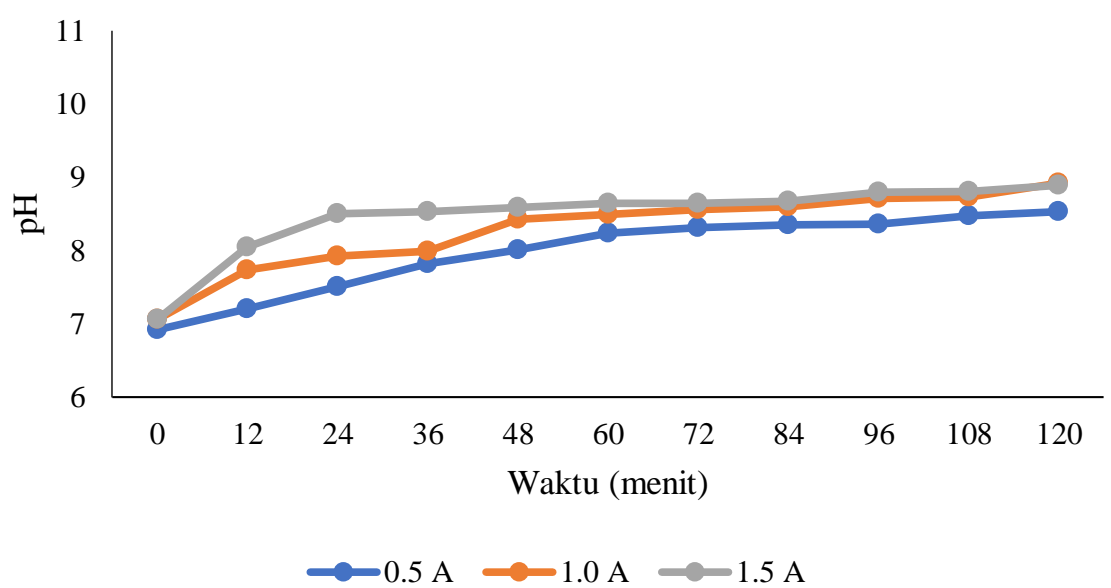

Gambar 2. Kurva perubahan $\mathrm{pH}$ pada waktu 2 jam Sumber: Hasil analisis, 2020

Berdasarkan Gambar 1 - Gambar 3, pada semua variasi terjadi peningkatan pH selama proses elektrokoagulasi. Besar kecilnya pengaruh $\mathrm{pH}$ tergantung pada besar arus listrik dan jumlah $\mathrm{Al}^{3+}$ yang terhidrolisis. Selama berlangsungnya proses elektrokoagulasi terjadi proses elektrodik yang mengakibatkan perubahan komposisi pada larutan elektrolit yaitu terjadinya kenaikan pH karena adanya pelepasan ion $\mathrm{OH}^{-}$dan gas $\mathrm{H}_{2}$ dari reaksi reduksi di katoda [10]. Proses yang terjadi pada elektrokoagulasi yaitu [11]:

Anoda (oksidasi):

Katoda (Reduksi)

$$
2 \mathrm{H}_{2} \mathrm{O} \rightarrow \mathrm{O}_{2}+4 \mathrm{H}^{+}+4 \mathrm{e}
$$

$$
2 \mathrm{H}_{2} \mathrm{O}+2 \mathrm{e} \rightarrow 2 \mathrm{OH}^{-}+\mathrm{H}_{2}
$$




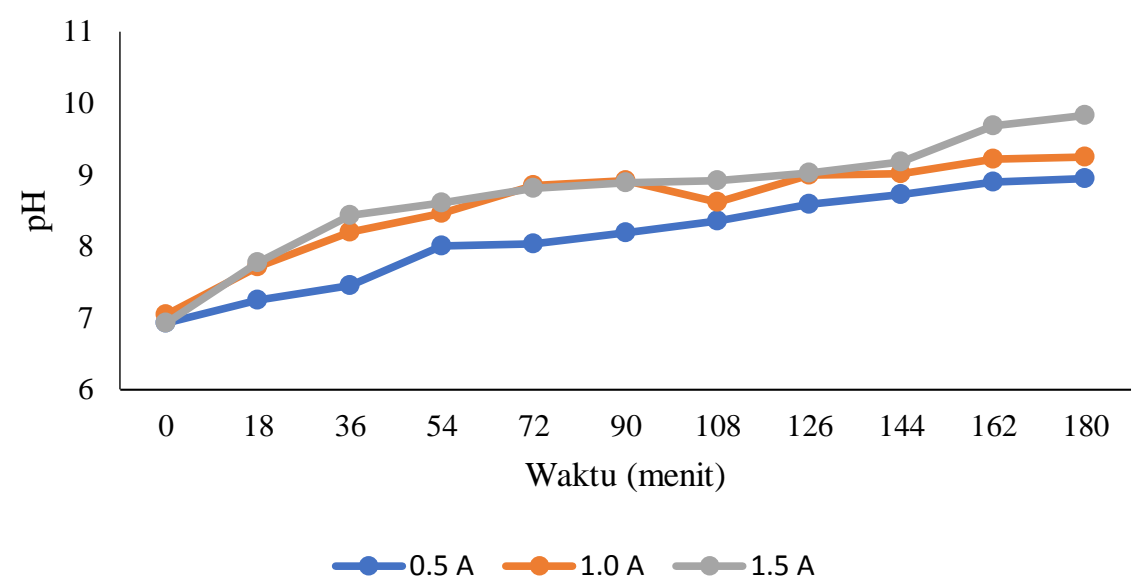

Gambar 3. Kurva perubahan $\mathrm{pH}$ pada waktu 3 jam Sumber: Hasil analisis, 2020

Pada proses elektrokoagulasi dihasilkan $\mathrm{H}^{+}$pada proses oksidasi $\mathrm{H}_{2} \mathrm{O}$ di anoda dan $\mathrm{OH}^{-}$pada proses reduksi $\mathrm{H}_{2} \mathrm{O}$ di katoda. Pada setiap variasi terjadi peningkatan $\mathrm{pH}$, hal ini menunjukkan bahwa produksi ion $\mathrm{OH}^{-}$yang lebih besar dibandingkan dengan ion $\mathrm{H}^{+}$.

\section{b. Perubahan Suhu}

Selama proses elektrokoagulasi, sampel air limbah mengalami peningkatan suhu. Perubahan suhu yang terjadi selama proses elektrokoagulasi yang dilakukan dapat dilihat pada Gambar 4 - Gambar 6.

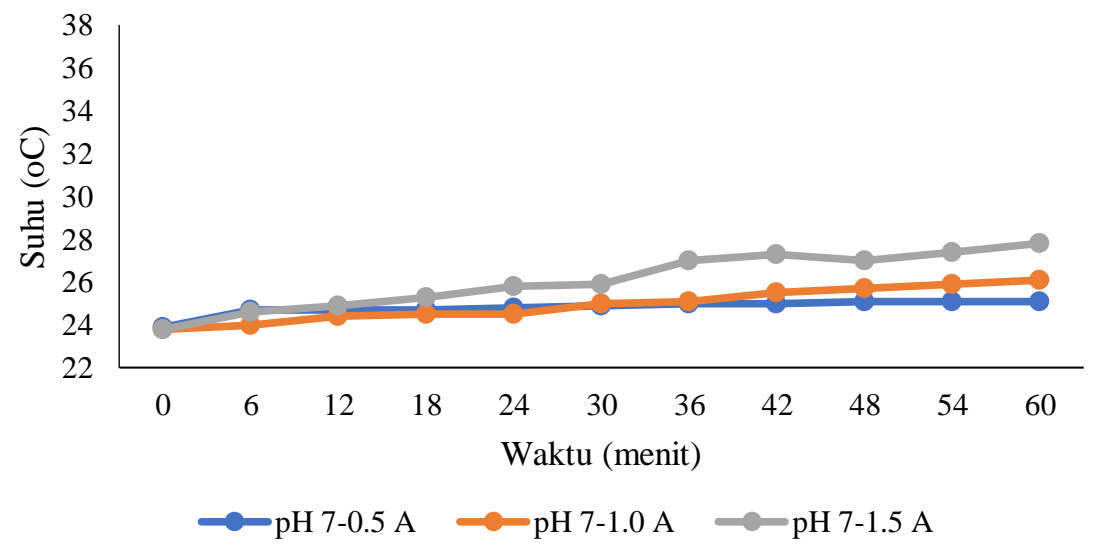

Gambar 4. Kurva perubahan suhu pada waktu 1 jam Sumber: Hasil analisis, 2020

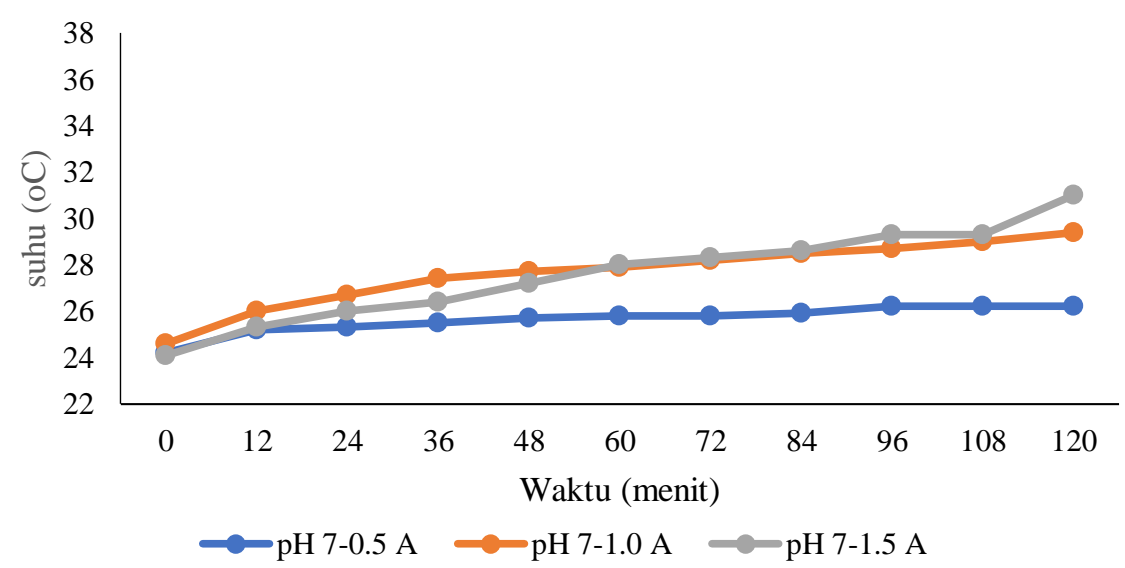

Gambar 5. Kurva perubahan suhu pada waktu 2 jam Sumber: Hasil analisis, 2020 


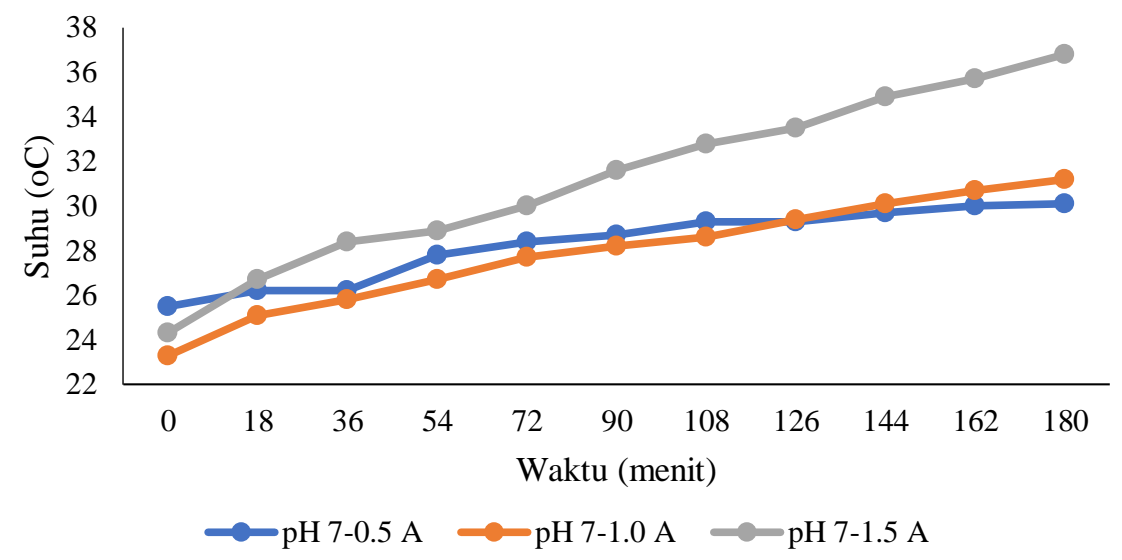

Gambar 6. Kurva perubahan suhu pada waktu 3 jam Sumber: Hasil analisis, 2020

Pada Gambar 4 - Gambar 6 menunjukkan semakin besar arus listrik menyebabkan peningkatan suhu pula. Peningkatan suhu pada proses elektrokoagulasi yang dilakukan terjadi karena pelepasan hidroksida logam $\mathrm{Al}^{3+}$. Pelepasan ion $\mathrm{Al}^{3+}$ menghasilkan kenaikan $\mathrm{pH}$ selama proses elektrokoagulasi dan melepaskan energi berupa panas yang mempengaruhi kenaikan kecepatan reaksi [12]. Sehingga semakin lama proses elektrokoagulasi maka terjadi peningkatan suhu yang tinggi karena selama proses melepaskan energi berupa panas [13]. Hal tersebut dapat lihat pada reaksi [14]:

$$
\left[\mathrm{Al}^{3+}+3 \mathrm{H}_{2} \mathrm{O} \rightarrow \mathrm{Al}(\mathrm{OH})_{3}+3 \mathrm{H}^{+}+3 \mathrm{e}-\right]^{*} \quad \Delta \mathrm{H}=-419,6 \mathrm{~kJ}
$$

Berdasarkan reaksi pembentukan $\mathrm{Al}(\mathrm{OH})_{3}$ diperoleh $\Delta \mathrm{H}_{\text {reaksi }}-419,6 \mathrm{~kJ}$. Nilai $\Delta \mathrm{H}_{\text {reaksi }}$ yang bernilai negatif menunjukkan bahwa reaksi tersebut merupakan reaksi eksotermis. Reaksi eksotermis menghasilkan panas yang dibuang ke lingkungan sekitarnya sehingga suhu larutan meningkat [15].

\section{c. Perubahan Massa Anoda}

Proses elektrokoagulasi pada penelitian ini menggunakan lempengan Alumunium sebagai elektrodanya. Alumunium digunakan sebagai elektroda karena alumunium baik dalam menghantarkan listrik dan tahan korosi. Elektroda dalam proses elektrokoagulasi berfungsi sebagai penghantar arus listrik ke dalam larutan agar terjadi reaksi kimia di dalam larutan yaitu terjadinya reaksi reduksi oksidasi (redoks) [16].

Pada anoda terjadi reaksi oksidasi dan pada katoda terjadi reaksi reduksi. Alumunium mengalami oksidasi yang menyebabkan terjadinya peluruhan yang menghasilkan ion $\mathrm{Al}^{3+}$. Anoda melepaskan ion-ion positif dan katoda menangkap ion-ion positif sehingga ion-ion positif ini akan terus berkurang saat dialiri listrik. Semakin besar arus listrik yang diberikan maka anoda yang teroksidasi semakin banyak oleh karena itu terjadi pengurangan massa anoda [17]. Besarnya massa alumunium yang berkurang secara teoritis dan yang terjadi pada percobaan dapat dilihat pada Gambar 7.

Berdasarkan Gambar 7, terdapat perbedaan antara percobaan dan teori. Massa anoda yang berkurang pada percobaan lebih kecil dibandingkan masa anoda yang yang dihitung berdasarkan teori. Perbedaan ini disebabkan karena terjadinya perubahan energi menjadi panas, hilangnya arus karena hambatan material penghubung dan kualitas material anoda yang digunakan [18].

Massa anoda yang berkurang pada saat elektrokogulasi akan semakin besar bila arus listrik diperbesar dan waktu diperpanjang. Hal ini sesuai dengan Hukum Faraday 1, semakin besar kuat arus listrik dan semakin lama proses maka semakin banyak logam aluminium yang teroksidasi. Anoda akan teroksidasi dan menjadi kation yang larut dalam air [19]. 


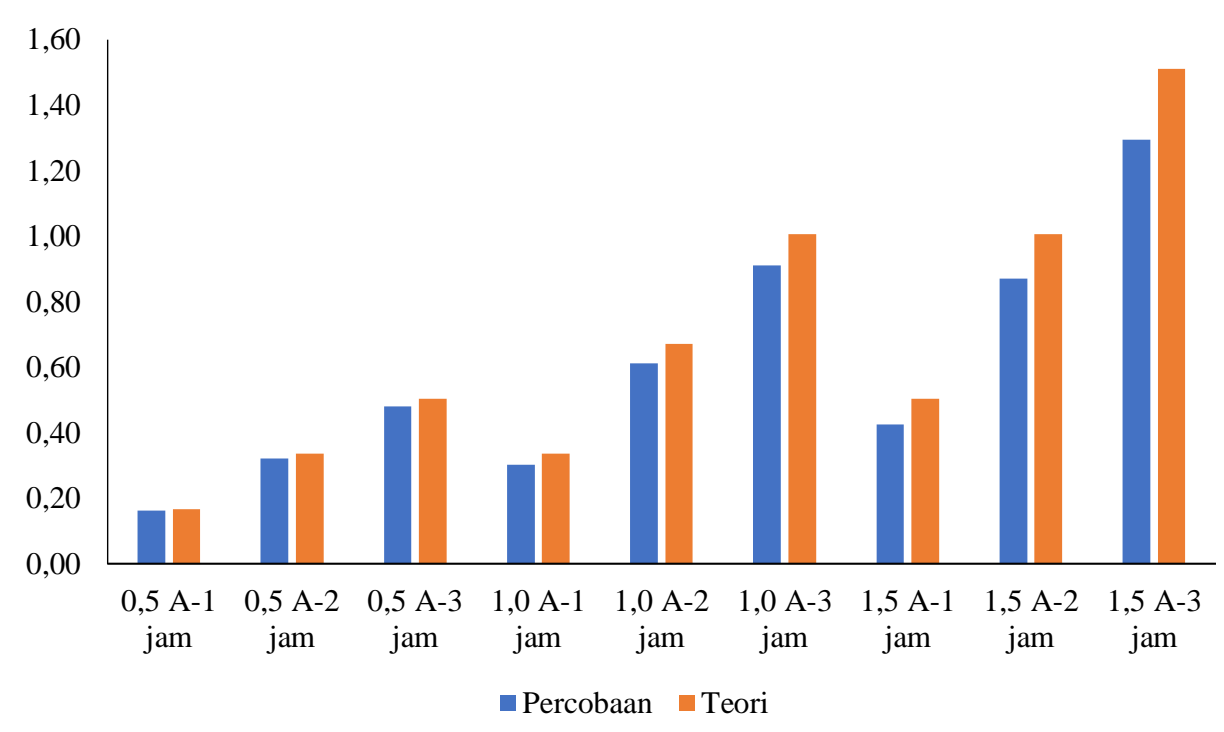

Gambar 7. Kurva pengurangan massa anoda Sumber: Hasil analisis, 2020

\section{Analisa Kualitas Air Limbah}

Hasil pengukuran sampel limbah cair sebelum dilakukan pengolahan air limbah secara elektrokoagulasi, konsentrasi krom total sampel yaitu 245,1 mg/l. Konsentrasi krom total sebelum dan setelah dilakukan pengolahan secara elektrokoagulasi dengan variasi arus listrik dan waktu pengolahan dapat dilihat pada Gambar 8.



Gambar 8. Analisis konsentrasi krom total Sumber: Hasil analisis, 2020

Pada Gambar 8 terjadi penurunan konsentrasi krom total setelah dilakukan pengolahan secara elektrokoagulasi. Proses elektrokoagulasi pada penelitian ini menggunakan lempengan Alumunium sebagai pasangan elektroda. Penggunaan aluminium sebagai elektroda karena mempunyai sifat sebagai koagulan yang baik. Proses elektrokoagulasi pada prinsipnya berdasarkan pada proses sel elektrolisis. Sel elektrolisis merupakan suatu alat yang dapat mengubah energi listrik DC (direct current) untuk menghasilkan reaksi elektrolit. Sel elektrolisis mempunyai dua elektroda, yaitu katoda dan anoda [10]. Reaksi yang terjadi pada sel elektroda adalah [10]:

Reaksi pada Katoda:

Reaksi pada Anoda :

$$
2 \mathrm{H}_{2} \mathrm{O}+2 \mathrm{e}^{-} \rightarrow \mathrm{H}_{2}+2 \mathrm{OH}^{-}
$$

$$
\mathrm{Al} \rightarrow \mathrm{Al}^{+3}+3 \mathrm{e}
$$


Proses oksidasi di anoda mengakibatkan terlarutnya alumunium menjadi ion $\mathrm{Al}^{+3}$. Ion $\mathrm{Al}^{+3}$ yang terbentuk ini, di dalam larutan akan mengalami reaksi hidrolisis, menghasilkan $\mathrm{Al}(\mathrm{OH})_{3} . \mathrm{Al}(\mathrm{OH})_{3}$ yang terbentuk dalam larutan dapat berfungsi sebagai koagulan untuk proses koagulasi-flokulasi yang terjadi pada proses selanjutnya di dalam sel [14].

Reaksinya [14] :

$$
\mathrm{Al}^{3+}+3 \mathrm{H}_{2} \mathrm{O} \rightarrow \mathrm{Al}(\mathrm{OH})_{3}+3 \mathrm{H}^{+}
$$

Pada reaksi yang terjadi di proses elektrokoagulasi, $\mathrm{Al}(\mathrm{OH})_{3}$ yang terbentuk akan menjebak secara logam $\mathrm{Cr}$ yang ada di dalam limbah [14]. Pada katode, dihasilkan gas hidrogen $\left(\mathrm{H}_{2}\right)$ yang berfungsi untuk menaikkan flok-flok tersuspensi kemudian dapat terflotasi, sehingga terpisahkan dari air [20].

Hal ini disebabkan semakin banyaknya suplai kation $\mathrm{Al}^{3+}$ maka semakin banyak kation yang menyerap atau mengikat larutan. Hal tersebut berarti bahwa semakin meningkatnya pengurangan masa anoda aluminium mengakibatkan penurunan kadar krom dalam limbah cair semakin meningkat [19]. Pengurangan masa aluminium dipengaruhi oleh arus listrik yang diberikan dan waktu yang digunakan pada proses elektrokoagulasi.

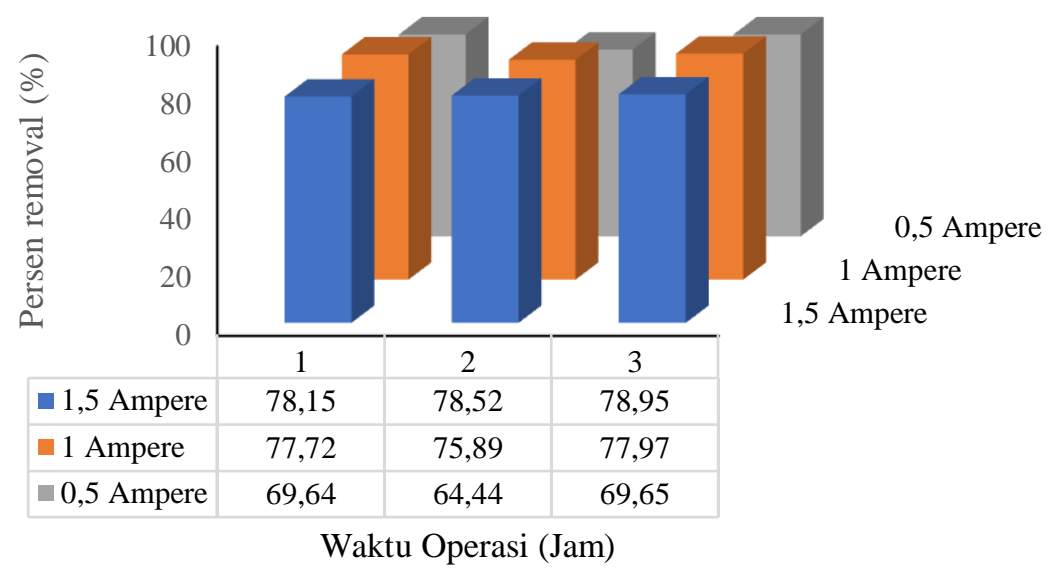

Gambar 9. Kurva efisiensi pengurangan konsentrasi krom total Sumber: Hasil analisis, 2020

Berdasarkan Gambar 9 dapat dilihat bahwa proses elektrokoagulasi yang dilakukan pada $\mathrm{pH} 7$ berdasarkan variasi arus listrik $(0,5 \mathrm{~A}, 1 \mathrm{~A}, 1,5 \mathrm{~A})$ dan waktu pengolahan (1 jam, 2 jam, 3 jam) dapat menyisihkan krom total dari 64,44\% sampai 78,95\%. Dari 9 variasi percobaan, didapatkan variasi yang terbaik untuk proses elektrokoagulasi yaitu pada arus listrik 1,5 A dan waktu proses 3 jam yang dapat menyisihkan konsentrasi krom dari $245,1 \mathrm{mg} / \mathrm{L}$ menjadi $51,6 \mathrm{mg} / \mathrm{L}$. Pada variasi ini dapat menyisihkan konsentrasi krom sebesar 193,5 mg/L. Hal ini dipengaruhi oleh arus listrik dan waktu operasi yang digunakan. Semakin besar arus listrik dan semakin lama waktu yang digunakan maka efisiensi penyisihan krom akan semakin tinggi.

\section{Kesimpulan}

Pada proses elektrokoagulasi yang dilakukan terjadi peningkatan $\mathrm{pH}$, peningkatan suhu, dan penurunan masa anoda. Berdasarkan percobaan pada 9 variasi proses elektrokoagulasi yang dilakukan pada variasi arus listrik dan waktu operasi didapatkan bahwa semakin besar arus listrik dan semakin lama waktu yang digunakan maka efisiensi penyisihan krom akan semakin tinggi. Efisiensi penyisihan krom total yang paling tinggi yaitu 78,95\% pada variasi arus listrik 1,5 A dan waktu 3 jam, yang dapat menyisihkan krom total dari $245,1 \mathrm{mg} / \mathrm{L}$ menjadi $51,6 \mathrm{mg} / \mathrm{L}$. 


\section{Referensi}

[1] F. A. Sari and S. Rahayu, "Kajian Dampak Keberadaan Industri PT. Korindo Ariabima Sari Di Kelurahan Mendawai, Kabupaten Kotawaringin Barat," Teknik PWK (Perencanaan Wilayah Kota), vol. 3, no. 1, pp. 106-116, 2014.

[2] H. Harmami, I. Ulfin, and N. C. Wahyulis, "Optimasi Tegangan pada Proses Elektrokoagulasi Penurunan Kadar Kromium dari Filtrat Hasil Hidrolisis Limbah Padat Penyamakan Kulit," Jurnal Sains dan Seni ITS, vol. 3, no. 2, p. 15468, 2014.

[3] A. Asmadi, S. Endro, and W. Oktiawan, "Pengurangan chrom $(\mathrm{Cr})$ dalam limbah cair industri kulit pada proses tannery menggunakan senyawa alkali $\mathrm{Ca}(\mathrm{OH})$ 2, $\mathrm{NaOH}$ dan $\mathrm{NaHCO} 3$ (Studi Kasus PT. Trimulyo Kencana Mas Semarang)," Jurnal Air Indonesia, vol. 5, no. 1, 2009.

[4] S. Sugihartono, "Pemisahan krom pada limbah cair industri penyamakan kulit menggunakan gelatin dan flokulan anorganik," Majalah Kulit, Karet, Dan Plastik, vol. 32, no. 1, pp. 21-30, 2016.

[5] D. T. Moussa, M. H. El-Naas, M. Nasser, and M. J. Al-Marri, "A comprehensive review of electrocoagulation for water treatment: Potentials and challenges," Journal of environmental management, vol. 186, pp. 24-41, 2017.

[6] E. Hartati, M. Sutisna, and W. Nursandi, "Perbaikan Kualitas Air Limbah Industri Farmasi Menggunakan Koagulan Biji Kelor (Moringa Oleifera Lam) Dan Pac (Poly Alumunium Chloride)," Jurnal Teknologi Lingkungan Universitas Trisakti, vol. 4, no. 3, pp. 68-73, 2008.

[7] T. Hernaningsih, "Reviews of Electrocoagulation Process on Waste Water Treatment Technology," Jurnal Rekayasa Lingkungan, vol. 9, no. 1, 2016.

[8] A. Deghles and U. Kurt, "Hydrogen gas production from tannery wastewater by electrocoagulation of a continuous mode with simultaneous pollutants removal," J Appl Chem, vol. 10, no. 3, pp. 40-50, 2017.

[9] M. Aboulhassan, H. El Ouarghi, S. Ait Benichou, A. Ait Boughrous, and F. Khalil, "Influence of experimental parameters in the treatment of tannery wastewater by electrocoagulation," Separation Science and Technology, vol. 53, no. 17, pp. 2717-2726, 2018.

[10] F. Hanum, R. Tambun, M. Y. Ritonga, and W. W. Kasim, "Aplikasi elektrokoagulasi dalam pengolahan limbah cair pabrik kelapa sawit," Jurnal Teknik Kimia USU, vol. 4, no. 4, pp. 13-17, 2015.

[11] P. Afifah, "Pengaruh Logam Tembaga dalam Penyisihan Logam Nikel dari Larutannya menggunakan Metode Elektrodeposisi," Reka Lingkungan, vol. 2, no. 2, 2014.

[12] P. K. Holt, G. W. Barton, and C. A. Mitchell, "The future for electrocoagulation as a localised water treatment technology," Chemosphere, vol. 59, no. 3, pp. 355-367, 2005.

[13] B. Hari P and M. Harsanti, "Pengolahan Limbah Cair Tekstil Menggunakan Proses Elektrokoagulasi dengan Sel Al-Al," Prosiding Seminar Nasional Teknik Kimia "Kejuangan", 2010.

[14] P. Prayitno and E. Kismolo, "Percobaan awal proses elektrokoagulasi sebagai metode alternatif pada pengolahan limbah cair," Pusat Teknologi Akselarator, 2012.

[15] D. Djaenudin and M. Syafila, "Perolehan Kembali Perak dari Limbah Sisa Analisis COD Menggunakan Metoda Elektrolisis," Jurnal Purifikasi, vol. 10, no. 1, pp. 59-70, 2009.

[16] N. C. Wahyulis, I. Ulfin, and H. Harmami, "Optimasi tegangan pada proses elektrokoagulasi penurunan kadar kromium dari filtrat hasil hidrolisis limbah padat penyamakan kulit," Jurnal Sains dan Seni ITS, vol. 3, no. 2, pp. C9-C11, 2014.

[17] N. P. Setianingrum, A. Prasetya, and S. Sarto, "Pengaruh Tegangan Listrik, Jarak Antar Elektroda dan Waktu Kontak Terhadap Penurunan Zat Warna Remazol Red Rb Menggunakan Metode Elektrokoagulasi," in Seminar Nasional Teknologi Pengelolaan Limbah XV tahun 2017, 2017: Pusat Teknologi Limbah Radioaktif.

[18] A. Mukimin, "Pengolahan limbah industri berbasis logam dengan teknologi elektrokoagulasi flotasi," Program Pascasarjana Universitas Diponegoro, 2006.

[19] L. R. Sahlan, "Kadar Krom (Cr) dalam Limbah Cair Industri Penyamakan Kulit dengan Metode Elektrokoagulasi secara Batch," Fakultas Teknik Program Studi Teknik Kimia Universitas Pembangunan Nasional Yogyakarta, 2016.

[20] I. Zongo, J.-P. Leclerc, H. A. Maiga, J. Wethe, and F. Lapicque, "Removal of hexavalent chromium from industrial wastewater by electrocoagulation: A comprehensive comparison of aluminium and iron electrodes," Separation and purification Technology, vol. 66, no. 1, pp. 159-166, 2009. 